\title{
The impact of temperature and pump flow rate during selective cerebral perfusion on regional blood flow in piglets
}

\author{
Jian Wang, MD, PhD, ${ }^{\mathrm{a}}$ Richard M. Ginther, CCP, ${ }^{\mathrm{a}}$ Matthew Riegel, DVM, ${ }^{\mathrm{b}}$ Rong Huang, MS, ${ }^{\mathrm{c}}$ \\ Mahesh S. Sharma, MD, ${ }^{a}$ Kristine J. Guleserian, MD, ${ }^{a}$ and Joseph M. Forbess, MD ${ }^{\mathrm{a}}$
}

Objective: Ideal temperature and flow rate for selective cerebral perfusion (SCP) are not known. We examined regional organ perfusion in a piglet SCP model.

\begin{abstract}
Methods: Three groups underwent SCP at $30 \mathrm{~mL} / \mathrm{kg} / \mathrm{min}$ at different temperatures $\left(15^{\circ} \mathrm{C}, 25^{\circ} \mathrm{C}\right.$, and $\left.32^{\circ} \mathrm{C}\right)$ and 4 groups remained at $25^{\circ} \mathrm{C}$ for SCP at different flow rates $(10,30,50$ and $75 \mathrm{~mL} / \mathrm{kg} / \mathrm{min})$. Fluorescent microspheres were injected at 5 minutes of normothermic cardiopulmonary bypass (CPB), immediately before SCP, SCP 45 minutes, SCP 90 minutes, and 2 hours after CPB. Brain and lower body organs were collected to examine regional blood flow $(\mathrm{RBF}, \mathrm{mL} / \mathrm{min} / \mathrm{g})$.
\end{abstract}

Results: At 2 hours after $\mathrm{CPB}, \mathrm{RBF}$ of the $32^{\circ} \mathrm{C}$ group was higher than that of the $15^{\circ} \mathrm{C}$ group $(P<.05)$ at the caudate nucleus and hippocampus; $\mathrm{RBF}$ of the $32^{\circ} \mathrm{C}$ group was higher than that of the $25^{\circ} \mathrm{C}$ and $15^{\circ} \mathrm{C}$ groups $(P<.05)$ at the neocortex. No significant difference in RBF was observed among any of the $25^{\circ} \mathrm{C}$ groups at different flow rates. Also, there was no significant difference between the RBF to the left and right sides of brain in either the temperature or flow rate groups. RBF did significantly increase with temperature in the liver and quadriceps during SCP $(P<.05)$. At the kidney, RBF at SCP 90 minutes was significantly higher than that at SCP 45 minutes when all temperature groups were combined $(P<.05)$.

Conclusions: SCP at $32^{\circ} \mathrm{C}$ provides higher brain RBF 2 hours after $\mathrm{CPB}$. Increasing SCP flow rate does not increase RBF significantly at $25^{\circ} \mathrm{C}$. Higher temperature during SCP results in improved RBF to the liver and quadriceps. (J Thorac Cardiovasc Surg 2013;145:188-95)

Cerebral protection during aortic arch reconstruction remains a major challenge in pediatric cardiac surgery. Although hypothermic circulatory arrest (HCA) is known to be neuroprotective, the safe duration of HCA alone is limited and a significant number of children undergoing such operations may have neurologic complications. ${ }^{1}$ Antegrade selective cerebral perfusion (SCP) is a cardiopulmonary bypass (CPB) technique in heavy clinical use. SCP provides a potentially more physiologic method of perfusion and may extend the safe time limits for aortic arch repair. HCA and SCP are sometimes used in combination for neuroprotection in infants and children. There is some clinical evidence that HCA supplemented by SCP improved neurologic outcomes when prolonged periods of HCA were required. ${ }^{2}$

From the Division of Pediatric Cardiothoracic Surgery, ${ }^{\text {a }}$ University of Texas South western Medical Center and Children's Medical Center, the Animal Resources Center, ${ }^{\mathrm{b}}$ University of Texas Southwestern Medical Center, and the Clinical Research Department, ${ }^{\mathrm{c}}$ Children's Medical Center, Dallas, Tex.

Disclosures: Authors have nothing to disclose with regard to commercial support.

Read at the 92nd Annual Meeting of The American Association for Thoracic Surgery, San Francisco, California, April 28-May 2, 2012.

Received for publication May 8, 2012; revisions received Sept 12, 2012; accepted for publication Sept 21, 2012; available ahead of print Nov 9, 2012

Address for reprints: Joseph M. Forbess, MD, Division of Pediatric Cardiothoracic Surgery, University of Texas Southwestern Medical Center, Children's Medical Center, 1935 Medical District Dr, Suite C3211, Dallas, TX 75235 (E-mail: Joseph.Forbess@UTSouthwestern.edu). $0022-5223 / \$ 36.00$

Copyright @ 2013 Published by Elsevier Inc. on behalf of The American Association for Thoracic Surgery

http://dx.doi.org/10.1016/j.jtcvs.2012.09.055
Although SCP is widely used for cerebral protection, technical issues relating to the use of hypothermic SCP, such as ideal temperature and flow rate, are still unresolved. There is also no information about the changes in regional blood flow (RBF) for different regions of the brain during SCP. Blood does return into the descending aorta to visceral organs through collaterals during SCP. However, limited information about the degree of blood flow in lower body organs during SCP is limited.

In this study, we used a piglet model of CPB and SCP to examine cerebral RBF changes, measured using fluorescent microspheres, at variable temperatures and pump rates. The technique of fluorescent microspheres has been used previously in the brain and other organs. ${ }^{3,4}$ We also sought to examine blood flow to various lower body organs during SCP in this model.

\section{MATERIALS}

\section{Experiment Design}

All animals received humane care in compliance with the "Guide for the Care and Use of Laboratory Animals" published by the National Institutes of Health (NIH publication no. 85-23, revised 1985), and all animal procedures were approved by the Institutional Animal Care and Use Committee at the University of Texas Southwestern Medical Center at Dallas.

Thirty Yorkshire piglets (4 weeks of age; weight, 4-11 kg) were used. Animals were assigned to 7 groups ( $n=5$ per group) Three groups underwent SCP for 90 minutes at $30 \mathrm{~mL} / \mathrm{kg} / \mathrm{min}$ at different temperatures $\left(15^{\circ} \mathrm{C}\right.$, $25^{\circ} \mathrm{C}$, and $32^{\circ} \mathrm{C}$ ) and 4 groups remained at $25^{\circ} \mathrm{C}$ for 90 minutes of SCP at 

Abbreviations and Acronyms
$\mathrm{CPB}=$ cardiopulmonary bypass
$\mathrm{HCA}=$ hypothermic circulatory arrest
$\mathrm{RBF}=$ regional blood flow
SCP $=$ selective cerebral perfusion

different pump flow rates $(10,30,50$, and $75 \mathrm{~mL} / \mathrm{kg} / \mathrm{min})$. After SCP, animals were rewarmed, weaned from $\mathrm{CPB}$, and allowed to recover for 2 hours. Fluorescent microspheres were injected at the following time points: 5 minutes of normothermic CPB, immediately before SCP, 45 minutes of SCP, 90 minutes of SCP, just after CPB, and 2 hours after CPB. Brain tissues (bilateral neocortex, hippocampus, cerebellum, caudate nucleus, and brain stem) and lower body organs (quadriceps, stomach, duodenum, liver, and kidney) were collected to examine RBF.

\section{Surgical and CPB Protocol}

The piglets were administrated intramuscular ketamine $(20 \mathrm{mg} / \mathrm{kg})$ and xylazine $(4 \mathrm{mg} / \mathrm{kg})$. After endotracheal intubation, the piglets were ventilated mechanically with a fraction of inspired oxygen of 0.21 . The ventilation rate and tidal volume were adjusted to maintain normal arterial $\mathrm{pH}$ and carbon dioxide pressure. Anesthesia was maintained with fentanyl $(25 \mu \mathrm{g} /$ $\mathrm{kg} / \mathrm{h})$, midazolam $(0.2 \mathrm{mg} / \mathrm{kg} / \mathrm{h})$, and pancuronium $(0.2 \mathrm{mg} / \mathrm{kg} / \mathrm{h})$ using infusion pumps. The animals were initially placed supine on a watercirculating heating blanket to prevent hypothermia. Temperature probes were placed in the nasopharynx and rectum. The right axillary artery was cannulated for reference blood sampling and the right femoral artery was cannulated for measurement of artery blood pressure. A median sternotomy was performed. After administration of heparin (400 IU/kg), the ascending aorta was cannulated with a single $10 \mathrm{~F}$ arterial cannula, and the right atrium was cannulated with a single $18 \mathrm{~F}$ cannula. As a port for fluorescent microsphere injection, a 3-way stopcock was attached to the arterial cannula. Tourniquets were placed around the proximal innominate and left carotid arteries.

The CPB circuit consisted of a roller pump (Cardiovascular Instrument Corp, Wakefield, Mass), a Baby RX05 hollow membrane oxygenator, Capiox AF02 arterial line filter, CDI 500 blood gas monitor, HPH400 hemoconcentrator (Terumo Cardiovascular Systems, Ann Arbor, Mich), and sterile $1 / 4$-inch polyvinyl chloride tubing. The circuit was primed with Plasma-Lyte-A electrolyte solution (Abbott Laboratories, North Chicago, Ill), heparin (3000 IU), sodium bicarbonate (15 mEq), methylprednisolone (30 mg/kg), mannitol $(0.5 \mathrm{mg} / \mathrm{kg})$, furosemide $(0.25 \mathrm{mg} / \mathrm{kg})$, and fresh whole blood previously harvested from a donor pig. Hemoconcentration was used to maintain a hematocrit value of greater than $30 \%$ during CPB. At 5 minutes of full-flow $(100 \mathrm{~mL} / \mathrm{kg} / \mathrm{min})$ normthermic CPB, a $0.2 \mathrm{mg} / \mathrm{kg}$ dose of phentolamine was administered and the animal was cooled to desired temperature. The $\mathrm{pH}$-stat management strategy was used. Low flow of carbon dioxide was added to the oxygenator to maintain a temperature-corrected $\mathrm{pH}$ of 7.4. All animals were cooled for a minimum of 25 minutes to reach the target nasopharyngeal and rectal temperatures. When the desired core temperature was reached, the arterial cannula was advanced into the innominate artery and the proximal innominate was snugged to the cannula using a vascular tourniquet kit. At the same time, the left carotid artery was occluded. The ascending aorta was not crossclamped and myocardial protection was afforded by applying topical iced saline slush in the pericardium during the 90-minute interval of SCP.

After 90 minutes of SCP, full-flow ( $100 \mathrm{~mL} / \mathrm{kg} / \mathrm{min}$ ) CPB was reinstituted by pulling the arterial cannula back into aorta. The animals were warmed for a minimum of 25 minutes until the core temperature reached approximately $37^{\circ} \mathrm{C}$. The heart was defibrillated as necessary at a nasopharyngeal temperature of $30^{\circ} \mathrm{C}$. The animals were weaned from $\mathrm{CPB}$, and the arterial and venous cannulas were removed. Protamine $(5 \mathrm{mg} / \mathrm{kg})$ was administered intravenously.

\section{Microsphere Injections and Tissues Processing}

Six fluorescent microsphere injections were performed in each animal, using 6 different colors of $15-\mu \mathrm{m}$-diameter microspheres: Coral-High, Purple-High, Pink-High, Yellow-High, Coral-Medium, and Purple-Medium. At each time point, approximately 2 million microspheres were injected and flushed with 5-mL saline solution. To allow calculation of absolute blood flow rates, we withdrew a reference blood sample from the right axillary artery into syringes at $5 \mathrm{~mL} / \mathrm{min}$ with a Harvard withdrawal pump (Harvard Bioscience, Inc, Holliston, Mass) beginning at 10 seconds and continuing until 2 minutes after injection.

After the animals had been humanely killed and the skull removed, the left and right cerebral hemispheres were divided. Tissue samples were taken for microsphere counts at Interactive Medical Technologies Ltd, Irvine, California. The microspheres were recovered from the tissues by sedimentation and from the blood by using a commercial protocol. RBF was then calculated from the intensity of fluorescence microspheres in blood and tissue samples using this formula: $\mathrm{RBF}(\mathrm{mL} / \mathrm{min} / \mathrm{g})=\left(\mathrm{R} \times \mathrm{I}_{\mathrm{T}}\right) /$ $\left(I_{R} \times W t\right)$, where $R$ is the rate at which the reference blood samples was withdrawn, $I_{T}$ is the fluorescence intensity of the tissue samples, $I_{R}$ is the fluorescence intensity of the blood samples, and $\mathrm{Wt}$ is the weight of the tissue sample.

\section{Statistics}

Results are expressed as mean \pm standard deviation. All statistical analyses were performed with SAS software (SAS Institute, Inc, Cary, NC). Analysis of variance was used to compare baseline physiologic parameters among temperature and flow rate groups. Mixed model was used to analyze blood flow change from baseline among temperature and flow rate groups. A paired $t$ test was used to compare the blood flow change between SCP at 45 minutes and 90 minutes.

\section{RESULTS}

No significant differences were seen in the physiologic parameters of either the temperature or flow rate groups at baseline (Tables 1 and 2).

During the SCP phase, all regions of brain showed slightly higher brain blood flow in the $32^{\circ} \mathrm{C}$ group compared with the $15^{\circ} \mathrm{C}$ and $25^{\circ} \mathrm{C}$ groups; however, there was no significant difference. At 2 hours after CPB (Figure 1), the $\mathrm{RBF}$ of the $32^{\circ} \mathrm{C}$ group was higher than that of the $15^{\circ} \mathrm{C}$ group $(P<.05)$ in the caudate nucleus and hippocampus; RBF of the $32^{\circ} \mathrm{C}$ group was higher than that of the $25^{\circ} \mathrm{C}$ and the $15^{\circ} \mathrm{C}$ groups $(P<.05)$ at the neocortex. In the cerebellum and brain stem, RBFs were higher in the $32^{\circ} \mathrm{C}$ group compared with the $25^{\circ} \mathrm{C}$ and the $15^{\circ} \mathrm{C}$ groups at 2 hours after $\mathrm{CPB}$; however, there was no significant difference $\left(P=.31\right.$ vs $25^{\circ} \mathrm{C}$ and $P=.07$ vs $15^{\circ} \mathrm{C}$ groups at the cerebellum; $P=.46$ vs $25^{\circ} \mathrm{C}$ and $P=.27$ vs $15^{\circ} \mathrm{C}$ groups at the brain stem).

No significant association was observed between SCP flow rate and $\mathrm{RBF}$ at a fixed temperature of $25^{\circ} \mathrm{C}$ in all investigated regions of the brain (Figure 2). No significant difference in RBF to the left or right sides of brain tissues was observed in either temperature or flow rate groups. 
TABLE 1. Baseline physiology parameters of temperature groups

\begin{tabular}{lccc}
\hline & Temp 15 ${ }^{\circ} \mathbf{C}$ & Temp 25 $^{\circ} \mathbf{C}$ & Temp 32 $^{\circ} \mathbf{C}$ \\
\hline Weight $(\mathrm{kg})$ & $7.01 \pm 1.02$ & $6.57 \pm 0.48$ & $5.89 \pm 0.57$ \\
Temperature & $35.4 \pm 0.51$ & $34.58 \pm 1.05$ & $34.67 \pm 0.33$ \\
$\mathrm{MAP}(\mathrm{mm} \mathrm{Hg})$ & $79 \pm 5.18$ & $72.5 \pm 5.49$ & $67 \pm 4.93$ \\
Arterial pH & $7.35 \pm 0.04$ & $7.34 \pm 0.02$ & $7.37 \pm 0.03$ \\
$\mathrm{PaO}_{2}(\mathrm{~mm} \mathrm{Hg})$ & $278.6 \pm 56.02$ & $307 \pm 50.39$ & $346.33 \pm 41$ \\
$\mathrm{PaCO}_{2}(\mathrm{~mm} \mathrm{Hg})$ & $44 \pm 6.14$ & $49 \pm 3.21$ & $44.83 \pm 3.67$ \\
$\mathrm{Hb}(\mathrm{g} / \mathrm{dL})$ & $12.08 \pm 0.86$ & $12.45 \pm 0.56$ & $13.32 \pm 1.28$ \\
\hline
\end{tabular}

There is no significant difference among the 3 temperature groups. Temp, Temperature; $M A P$, mean arterial blood pressure; $\mathrm{PaO}_{2}$, arterial oxygen pressure; $\mathrm{PaCO}_{2}$, arterial carbon dioxide pressure; $\mathrm{Hb}$, hemoglobin

There was detectable flow in the lower body during SCP. $\mathrm{RBF}$ did significantly increase with temperature in the liver and quadriceps during SCP $(P<.05)$ (Figure 3, B). At the kidney, the flow rate at SCP 90 minutes was significantly higher than that at $\mathrm{SCP} 45$ minutes when all temperature groups were combined $(P<.05)$ (Figure $3, A)$.

\section{DISCUSSION}

All regions of the brain demonstrated higher blood flows at 2 hours after $\mathrm{CPB}$ in the $32^{\circ} \mathrm{C}$ group, although there is no significant difference at the cerebellum and the brain stem. During the SCP phase, we detected slightly higher brain blood flow in the $32^{\circ} \mathrm{C}$ group when compared with the $15^{\circ} \mathrm{C}$ and $25^{\circ} \mathrm{C}$ groups. Strauch and associates ${ }^{5}$ reported that a perfusion temperature of $30^{\circ} \mathrm{C}$ provided significantly more flow to all sampled regions of the brain compared with $25^{\circ} \mathrm{C}$ during SCP in the pig model. However, unlike our study results, they reported a gradual decline in cerebral flow with prolonged SCP. Imoto and colleagues ${ }^{6}$ reported on the performance of the Norwood procedure using SCP at mild hypothermia $\left(29^{\circ} \mathrm{C}-31^{\circ} \mathrm{C}\right)$. None of their patients was found to have neurologic deficits on early follow-up. Oppido and coworkers ${ }^{7}$ reported similar findings in a group of neonates undergoing aortic repair at mild hypothermia. Hypothermia is widely known to decrease cellular metabolic demands and lower oxygen consumption. However, deep hypothermia may be related to an increased inflammatory reaction to $\mathrm{CPB}$, increased blood viscosity and cell membrane rigidity, and impaired early recovery of postischemic blood flow and vascular autoregulation. ${ }^{8}$ Our data indeed showed lower blood flow at 2 hours after CPB compared with normothermic CPB at all regions of the brain in the $25^{\circ} \mathrm{C}$ and $15^{\circ} \mathrm{C}$ groups. This raises the possibility that those perfusion temperatures for SCP are less than ideal with regard to early postprocedural cerebral blood flow. Cerebral perfusion in the early postoperative period is influenced by many variables and has been to shown to be related to later neurologic outcomes. ${ }^{9}$ The neonatal brain is sensitive to hypoxicischemia, especially the neocortex and hippocampus. ${ }^{10}$ In humans, the neocortex is involved in higher functions such as the generation of motor commands, conscious thought, and language. The hippocampus plays an important role in the consolidation of information from short-term memory to long-term memory and spatial memory. Clinical evidence suggests that hypoxic ischemia in the neonates may damage these anatomic regions. $^{11}$

The optimal flow rate for SCP is the subject of considerable debate. Interestingly, we did not see a correlation between RBF and SCP flow rate at a fixed temperature of $25^{\circ} \mathrm{C}$. This was observed in the setting of $\mathrm{pH}$-stat $\mathrm{pH}$ management and the administration of the alpha-adrenergic blocking agent phentolamine. Meybohm and coworkers ${ }^{12}$ reported that both blood flow index and transcranial Doppler ultrasound suggested increased cerebral perfusion with an SCP of $50 \mathrm{~mL} / \mathrm{kg} / \mathrm{min}$ compared with the SCP $25 \mathrm{~mL} /$ $\mathrm{kg} / \mathrm{min}$ groups at $18^{\circ} \mathrm{C} \mathrm{CPB}$. However, Jonsson and associates ${ }^{13}$ examined blood flow during $\mathrm{SCP}$ at $20^{\circ} \mathrm{C}$ and demonstrated that lowering the SCP flow to $6 \mathrm{~mL} / \mathrm{kg} / \mathrm{min}$ in the pig model appeared to produce adequate perfusion. In theory, higher flows with SCP might increase the risk of cerebral edema and embolic phenomena. Where lower flow rates become "inadequate" is unclear. Haldenwang and colleagues ${ }^{14}$ described that high flow provided no benefit during long-term SCP at $25^{\circ} \mathrm{C}$ and that higher cerebral flow during the initial SCP period produced cerebral edema. From the existing reports, it is difficult to conclude what the optimal flow rate is for SCP.

Little attention has been paid to quantifying the blood flow to the lower body organs during SCP. In this piglet

TABLE 2. Baseline physiology parameters of flow rate groups

\begin{tabular}{|c|c|c|c|c|}
\hline & \multicolumn{4}{|c|}{ Flow rate groups } \\
\hline & $10 \mathrm{~mL} / \mathrm{kg} / \mathrm{min}$ & $30 \mathrm{~mL} / \mathrm{kg} / \mathrm{min}$ & $50 \mathrm{~mL} / \mathrm{kg} / \mathrm{min}$ & $75 \mathrm{~mL} / \mathrm{kg} / \mathrm{min}$ \\
\hline Weight (kg) & $7.13 \pm 0.57$ & $6.57 \pm 0.48$ & $7.12 \pm 0.8$ & $9.04 \pm 1.18$ \\
\hline Temperature & $34.75 \pm 0.48$ & $34.58 \pm 1.05$ & $35.33 \pm 0.21$ & $34.67 \pm 0.67$ \\
\hline MAP (mm Hg) & $69.25 \pm 4.99$ & $72.5 \pm 5.49$ & $73.33 \pm 3.96$ & $63.67 \pm 1.86$ \\
\hline Arterial pH & $7.31 \pm 0.04$ & $7.34 \pm 0.02$ & $7.32 \pm 0.03$ & $7.31 \pm 0.04$ \\
\hline $\mathrm{PaO}_{2}(\mathrm{~mm} \mathrm{Hg})$ & $301 \pm 18.8$ & $307 \pm 50.39$ & $293.33 \pm 11.39$ & $281.33 \pm 4.7$ \\
\hline $\mathrm{PaCO}_{2}(\mathrm{~mm} \mathrm{Hg})$ & $52.5 \pm 4.52$ & $49 \pm 3.21$ & $51.33 \pm 5.04$ & $55 \pm 6.66$ \\
\hline $\mathrm{Hb}(\mathrm{g} / \mathrm{dL})$ & $12.65 \pm 0.99$ & $12.45 \pm 0.56$ & $11.75 \pm 0.91$ & $11.37 \pm 0.45$ \\
\hline
\end{tabular}

There is no significant difference among the 4 flow rate groups. MAP, Mean arterial blood pressure; $\mathrm{PaO}_{2}$, arterial oxygen pressure; Paco $_{2}$, arterial carbon dioxide pressure; $\mathrm{Hb}$, hemoglobin. 

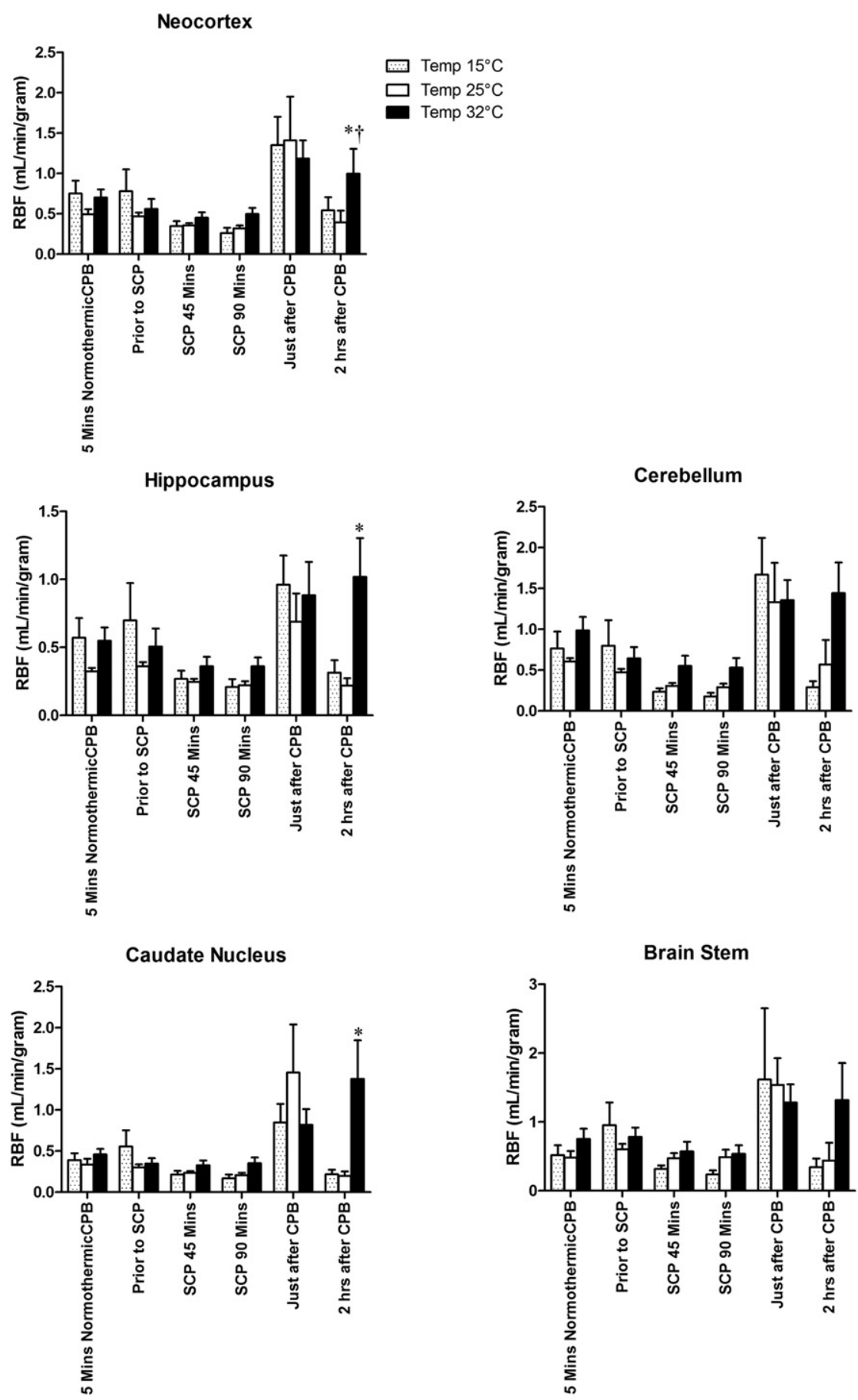

FIGURE 1. Regional blood flow $(R B F)$ at all investigated regions of brain. $* P<.05$ versus $15^{\circ} \mathrm{C}$ group; $\dagger P<.05$ versus $25^{\circ} \mathrm{C}$ group. $C P B$, Cardiopulmonary bypass; $S C P$, selective cerebral perfusion; Temp, temperature.

model, we detected blood flow in lower body organs during SCP. RBF did significantly increase with temperature in the liver and quadriceps during SCP among the temperature groups at a fixed pump flow rate. When all of these temperature groups were combined, the kidney showed higher RBF at SCP 90 minutes compared with SCP 45 minutes. This suggests the possibility of some positive adaptation to the conditions of SCP. Miyamoto and coworkers ${ }^{15}$ reported that the visceral organs were perfused to some extent through collaterals during SCP. Clinical series of SCP at mild hypothermia seem to indicate that the metabolic demands of the 


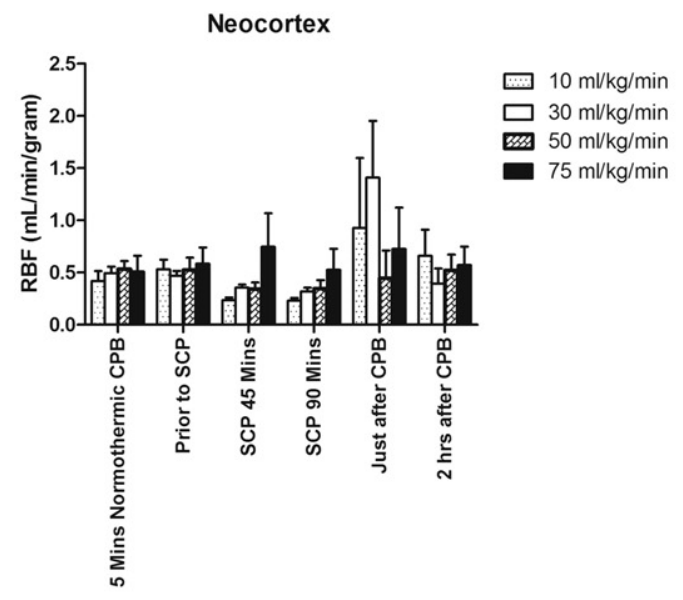

Hippocampus

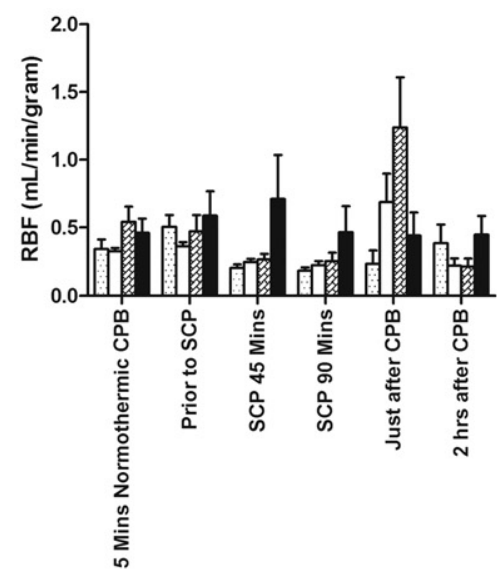

Caudate Nucleus

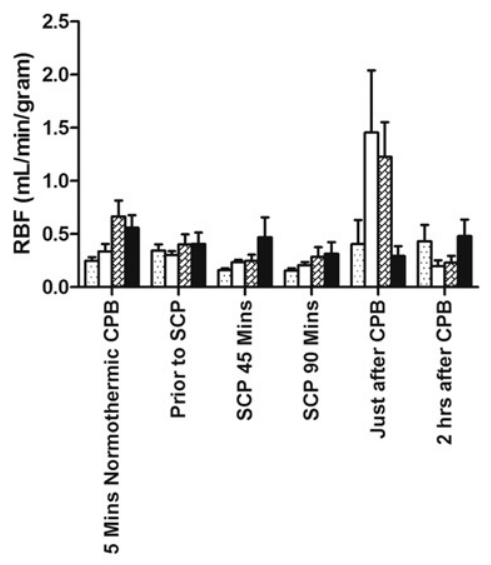

Cerebellum

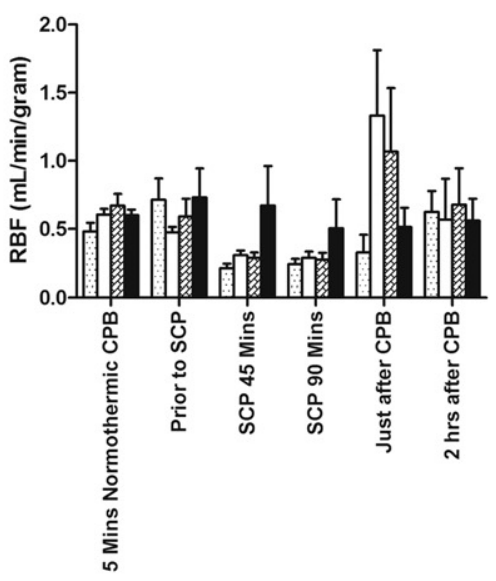

Brain Stem

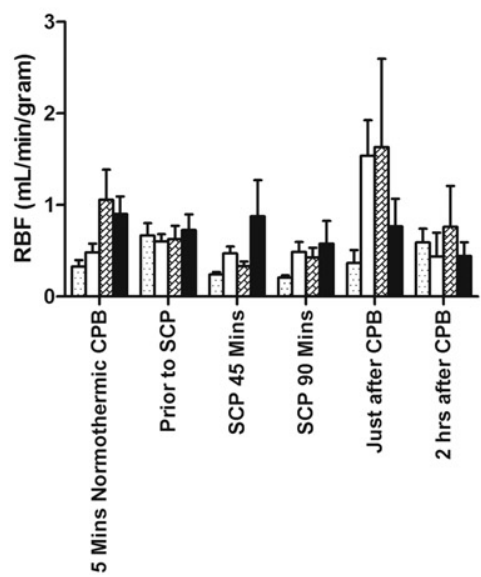

FIGURE 2. Regional blood flow $(R B F)$ at all investigated regions of brain. $C P B$, Cardiopulmonary bypass; $S C P$, selective cerebral perfusion.

lower body can be largely met with this perfusion strategy. ${ }^{16}$

There are increasing data suggesting that unilateral cerebral brain perfusion provides equal distribution of blood to both hemispheres. In our study, we did not find significant differences in RBF between the left and right sides of the brain, suggesting that significant flow occurs through the circle of Willis. This is in agreement with the data reported by Ye and associates ${ }^{17}$ wherein unilateral antegrade cerebral perfusion through the right axillary artery provided 

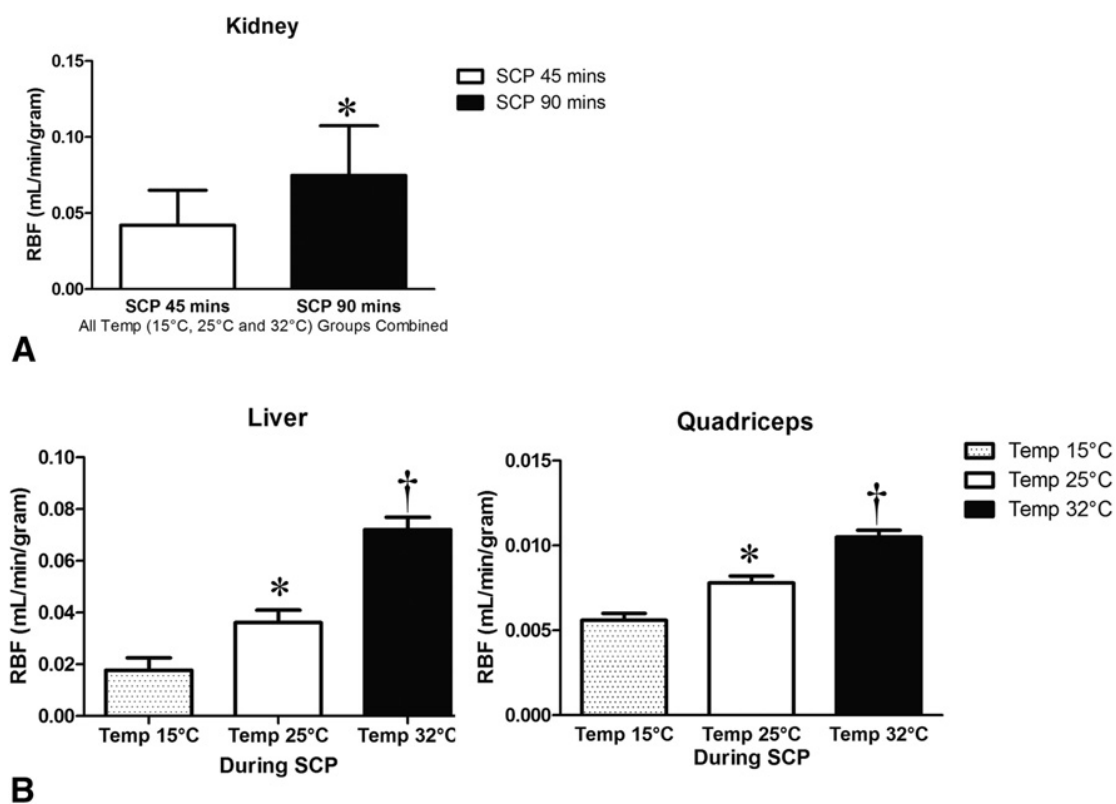

FIGURE 3. A, Regional blood flow $(R B F)$ during selective cerebral perfusion $(S C P)$ when all temperature groups combined. $* P<.05$ versus $\mathrm{SCP} 45$ minutes. B, RBF during SCP at liver and quadriceps. $* P<.05$ versus the $15^{\circ} \mathrm{C}$ group; $\dagger P<.05$ versus the $25^{\circ} \mathrm{C}$ group. $C P B$, Cardiopulmonary bypass; Temp, temperature.

uniform blood flow distribution to both hemispheres of the brain in pigs. In neonatal pigs, the ligation of 1 carotid artery has been shown to have no effect on the symmetry of cerebral blood flow during normal or ischemic conditions. ${ }^{18}$ No difference in histologic damage between the 2 brain hemispheres was seen in that study.

There are numerous theoretical advantages of SCP over deep HCA. Neocortical and hippocampal neurons have been shown to be selectively vulnerable to death after deep HCA in neonatal pigs. ${ }^{19}$ Loss of neurons in these regions is related to deficits of memory, emotional state, and motor function. SCP, as compared with deep HCA, has been shown to improve cortical oxygenation and prevent increases in the extracellular dopamine and hydroxyl radicals. Despite these and other apparent theoretical advantages, however, the efficacy of SCP in clinical use remains to be demonstrated. A single-institution clinical trial demonstrated that SCP was not associated with improved neurodevelopment outcomes when compared with deep HCA for patients undergoing the Norwood operation. ${ }^{20}$ SCP has become very widely used, but its benefits are difficult to define objectively. This short-term animal study of SCP appears to contribute to a body of increasing evidence that, if one uses SCP, mild hypothermia may be preferable to colder temperatures.

This study is subject to some limitations. One of the limitations is the fact that it is a short-term, nonsurvival animal model, so that we cannot offer insight into the relevance of the observed blood flow differences and neurologic outcome, for instance. Also, the variability of the porcine cerebrovascular anatomy may differ from that of humans. Pigs are generally known to have a circle of Willis linking the right and left cerebral circulations, but the magnitude and diameter of these communicating vessels may vary. This study is also limited by the relatively small sample size, as is typical in large animal preclinical model such as this.

\section{CONCLUSIONS}

In this piglet model of $\mathrm{SCP}$, mild hypothermia $\left(32^{\circ} \mathrm{C}\right)$ during SCP provides higher brain blood flow at 2 hours after CPB. Increasing SCP flow rate does not appear to increase $\mathrm{RBF}$ significantly at $25^{\circ} \mathrm{C}$. During SCP, there is detectable blood flow to the lower body. Higher temperature during SCP results in improved RBF to the liver and quadriceps. Unilateral cerebral perfusion is evenly distributed to both hemispheres in this piglet model of SCP.

We acknowledge the contributions of Dr Sandeep Singh to these animal studies. We also thank all technicians in Animal Resource Center of University of Texas Southwestern Medical Center for their valuable support.

\section{References}

1. Bellinger D, Wypij D, duPlessis A, Rappaport L, Jonas R, Wernovsky G, et al Neurodevelopment status at eight years in children with dextro-transpostion of the great arteries: the Boston Circulatory Arrest Trial. J Thorac Cardiovasc Surg. 2003;126:1385-96.

2. Fraser CD Jr, Andropoulos DB. Principles of antegrade cerebral perfusion during arch reconstruction in newborns/infants. Semin Thorac Cardiovasc Surg Pediatr Card Surg Annu. 2008;11:61-8. 
3. Eucker SA, Hoffman BD, Natrsh R, Ralston J, Armstead WM, Margulies SS Development of a fluorescent microsphere technique for rapid histological determination of cerebral blood flow. Brain Res. 2010;1326:128-34.

4. Van Oosterhout MFM, Willigers HMM, Reneman RS, Prinzen FW. Fluorescent microspheres to measure organ perfusion: validation of a simplified sample processing technique. Am J Physiol. 1995;269:H725-33.

5. Strauch JT, Haldenewang PL, Mullem K, Schmalz M, Liakopoulos O, Christ H, et al. Temperature dependence of cerebral blood flow for isolated regions of the brain during selective cerebral perfusion in pigs. Ann Thorac Surg. 2009;88: 1506-14.

6. Imoto Y, Kado H, Shiokawa Y, Minami K, Yasui H. Experience with the Norwood procedure without circulatory arrest. J Thorac Cardiovasc Surg. 2001; 122:879-82.

7. Oppido G, Napoleone CP, Turci S, Davies B, Frascaroli G, Martin-Suarez S, et al. Moderately hypothermic cardiopulmonary bypass and low-flow anterograde selective cerebral perfusion for neonatal aortic arch surgery. Ann Thorac Surg. 2006;82:2233-9.

8. Undar A. Effect of hypothermic cardiopulmonary bypass on blood viscoelasticity in pediatric cardiac patients. ASAIO J. 2005;51:522-4.

9. Tweddell JS, Ghanayem MS, Hoffman GM. Pro. NIRS is "standard of care" for postoperative management. Semin Thorac Cardiovasc Surg Pediatr Card Surg Аnпи. 2010;13:44-50.

10. Vannucci SJ, Hagberg H. Hypoxia-ischemia in the immature brain. $J$ Exp Biol. 2004;207:3149-54

11. Rutherford M, Ramenghi LA, Edwards AD, Brocklehurst P, Halliday H, Levene M, et al. Assessment of brain tissue injury after moderate hypothermia in neonates with hypoxic-ischemic encephalopathy: a nested substudy of a randomized controlled trial. Lancet Neurol. 2010;9:39-45.

12. Meybohm P, Hoffman G, Renner J, Boening A, Cavus E, Steinfath M, et al. Measurement of blood flow index during antegrade selective cerebral perfusion with near-infrared spectroscopy in newborn piglets. Anesth Analg. 2008;106:795-803.

13. Jonsson O, Morell A, Zemgulis V, Lundstrom E, Tovedal T, Einarsso GM, et al. Minimal safe arterial blood flow during selective antegrade cerebral perfusion at $20^{\circ}$ centigrade. Ann Thorac Surg. 2011;91:1198-205.

14. Haldenwang PL, Strauch JT, Amann I, Klein T, Sterner-Kock A, Christ H, et al. Impact of pump flow rate during selective cerebral perfusion on cerebral hemodynamics and metabolism. Ann Thorac Surg. 2010;90:1975-84.

15. Miyamoto Y, Fukui S, Kajiyama T, Mitsuno M, Yamamura M, Tanaka H, et al. Analysis of collateral blood flow to the lower body during selective cerebral perfusion: is three-vessel perfusion better than two-vessel perfusion? Eur J Cardiothorac Surg. 2009;35:684-8.

16. Zierer A, Detho F, Dzemali O, Aybek T, Moritz A, Bakhtiary F. Antegrade cerebral perfusion with mild hypothermia for aortic arch replacement: single center experience in 245 consecutive patients. Ann Thorac Surg. 2011;91: 1868-74.

17. Ye J, Dai G, Ryner LN, Kozlowski P, Yang L, Summers R, et al. Unilateral antegrade cerebral perfusion through the right axillary artery provides uniform flow distribution to both hemispheres of the brain: a magnetic resonance and histopathological study in pigs. Circulation. 1999;100(Suppl):II1309-35.

18. Laptook AR, Stonestree BS, Oh W. The effect of carotid artery ligation on brain blood flow in newborn piglets. Brain Res. 1983;276:51-4.

19. Kurh CC, Priestley M, Golden J, McCann J, Raghupathi R. Regional patterns of neuronal death after deep hypothermic circulatory arrest in newborn pigs. J Thorac Cardiovasc Surg. 1999;118:1068-77.

20. Goldberg CS, Bove EL, Devaney EJ, Mollen E, Schwartz E, Tindall S, et al. A randomized clinical trial of regional cerebral perfusion versus deep hypothermic circulatory arrest: outcomes for infants with functional single ventricle. J Thorac Cardiovasc Surg. 2007;133:880-7.

\section{Discussion}

Dr Christian Etz (Leipzig, Germany). I congratulate Dr Wang and his coauthors on an excellent experimental study on a very timely issue-the optimal flow for antegrade SCP at mild temperatures.

First, I have a couple of simple technical questions. What was the average weight of your animals? Approximately what flow/ body weight/minute does that translate to?
Dr Wang. Thank you. I know Dr Guleserian and Dr Sharma are in the room. Please feel free to interrupt me at any time.

We use animal area average weight as $6 \mathrm{~kg}$ at 4 weeks old.

Dr Etz. Four weeks old, $6 \mathrm{~kg}$, so it is more than 8 to $12 \mathrm{~mL} / \mathrm{min}$.

Your experimental data support the notion that unilateral SCP is sufficient to maintain equal perfusion to both hemispheres, a question that has been heavily debated clinically in the past. Although we do not know exactly to what degree piglets and humans do have the same anatomy of the circle of Willis, your findings are perfectly in line with the results of the largest clinical study in adults as presented yesterday at this very meeting by Dr Zierer and his coauthors from Germany on over 1000 patients undergoing antegrade SCP with up to 90 minutes of mild systemic HCA for complex aortic arch surgery. That group found that unilateral antegrade cerebral perfusion offers at least equal brain protection as bilateral antegrade cerebral perfusion and may be advantageous at least in the adult population as it might reduce embolism arising from surgical manipulation on arch vessels. I think this is one of the most important findings in your study.

There is a continuous trend toward higher temperatures during SCP even for complex aortic arch surgery. There is also growing concern that distal arrest during SCP at such high temperatures will not suffice to protect the tissues from ischemic damage. Therefore, I liked your analysis of RBF to the kidneys and the liver. However, you did not present data on the baseline flow to the viscera. Therefore, my second question is: What was the flow to the viscera during $\mathrm{SCP}$ as compared with the baseline flow during $\mathrm{CPB}$, a percentage maybe, and was it significantly different from baseline flow?

Dr Wang. To answer the first question, this is a large-animal prekinetic model. We used a small group size, with 5, and this is a short-term nonsurvival animal model. We cannot offer insight into the relevance of the blood flow difference and the neurologic outcome.

The second question?

Dr Etz. Was the flow during SCP that you measured to the liver and the kidneys different from the baseline flow? That would explain.

Dr Wang. You mean the kidneys, right?

Dr Etz. Okay. That brings me to my last question. The most sensitive of all tissue suffering ischemia during distal arrest is the spinal cord. Kamya and colleagues from the Hannover group demonstrated a 6-fold increase in mortality and paraplegia rate after prolonged distal circulatory arrest in a subgroup analysis of their series, and we have published our experimental data from 2 experiments from Dr Griepp's laboratory at Sinai. We found basically similar flows to the brain, but our experiments also did clearly demonstrate that there is zero blood flow to the spinal cord below the level of T8 once the clamp is placed. That resulted in devastating ischemic damage from paraplegia in a significant number of animals. I wondered whether you analyzed spinal cord tissue as well and what you found.

Dr Guleserian. Perhaps I might help to answer that question. No, we did not specifically look at the lower spinal cord, but I do think that is a very good point. When we try to translate these studies from the animal laboratory into clinical application, that is an important question to address down the road in survival studies. 
Dr Etz. You said that 2 hours after the procedure you had significantly higher flows to the viscera. We all know the hyperemic response after reperfusion, so are you sure it is a good thing to have?

Dr Guleserian. That is another good question. When we look at these different time points-one time point when immediately coming off bypass and then another at a delayed time point of 2 hours after bypass-metabolic demands are very different. The increased RBF may certainly be a reflection of the differences in those metabolic demands. Again, without survival studies and without larger numbers of animals, I think it is very difficult to tell and I would caution people from changing practice based solely on these and similar laboratory studies at this early time point. 